\title{
The Cultivation of Haemophilus pertussis in Partially Defined Liquid Media
}

\author{
By J. UNGAR, A. M. JAMES, P. W. MUGGLETON, \\ H. F. PEGLER AND E. G. TOMICH \\ Research Division, Glaxo Laboratories Ltd., Greenford, Middlesex
}

SUMMARY: Recently isolated virulent strains of Haemophilus pertussis grow well in a partially defined medium, but are more exacting in their growth requirements and conditions of growth than avirulent strains. The optimal pH for growth is 7.6-7.8. Mechanical agitation by stirring, spinning or aeration with either nitrogen or air, inhibits growth. Gaseous conditions, however, are critical in that there is an optimal relationship of surface area to volume of medium. Mechanical agitation and aeration stimulate the growth of avirulent strains.

Virulent strains require starch for growth, and there is a close relationship between virulence, specific agglutinability and starch requirement. Avirulent strains with low specific agglutinability grow readily in the absence of starch.

When starch in a standard medium is replaced by amylose, there is an increase in the final amount of growth. Amylopectin, glycogen and dextrans are about onethird as effective as starch; other carbohydrates, gums and inorganic adsorbents support little growth. Charcoal can replace starch, but has only c. $70 \%$ of its effect.

The amino-acid requirements of $\boldsymbol{H}$. pertussis are satisfied by acid-hydrolysate of casein, the optimal concentration being $7 \%$. All strains utilize aspartic and glutamic acids, serine, threonine, glycine, alanine and proline, but the rate of utilization is greater with virulent than with avirulent strains.

For good growth yeast extract is needed but can be replaced by nicotinamide, nicotinic acid or cozymase, provided sulphur-containing amino-acid is also present. Virulent strains of $\boldsymbol{H}$. pertussis require a sulphur-containing acid for growth, which may be supplied by yeast extract. Cysteine, cystine or glutathione, but not methionine, act as sources of essential sulphur.

For many years the optimal medium for the cultivation of Haemophilus pertussis has been the solid medium originally recommended by Bordet \& Gengou (1906). Strains grown on this medium maintain their biological properties unaltered for varying lengths of time. As the preparation of this medium necessitates the addition of either human or animal blood, Hornibrook attempted to replace it by a fluid medium (Hornibrook, 1939). Cohen $\&$ Wheeler (1945) modified Hornibrook's medium by adding copper and ferrous sulphates and increased the amounts of potassium phosphate, magnesium chloride and soluble starch. We used Cohen \& Wheeler's modification as a basal medium, having first confirmed that the organism grew well in it.

Our investigation was primarily intended to establish whether liquid partially defined culture media would permit growth of organisms suitable for vaccine production, that is to say, of bacilli that maintained the antigenic properties characteristic of a freshly isolated strain. It was considered probable that the physical and nutritional requirements of the organism would need careful control under the particular conditions of growth in the medium. The purpose of this communication is to report a detailed study of these requirements and of 
the conditions necessary for growth of strains having high antigenic activity. This activity was established by testing the vaccines made from them on rabbits and mice. The results of these tests will be reported elsewhere.

\section{EXPERIMENTAL}

Cultures. The strains of $\boldsymbol{H}$. pertussis were isolated from Bordet-Gengou cough plates and subcultured on fresh Bordet-Gengou slopes, which were incubated at $37^{\circ}$ and showed good growth on the second day. Each strain was freezedried (McLeod, 1944) immediately after isolation to avoid changes in biological properties, which often occurred with repeated subculture on Bordet-Gengou medium. We have stored strains in this way for several years without loss of virulence or agglutinability.

To determine the virulence of the strains, washed saline suspensions were made to contain $40,000 \times 10^{6} \mathrm{organisms} / \mathrm{ml}$. Suitable dilutions of this were made with saline and introduced in quantities of two drops into the nostrils of several anaesthetized mice (Burnet \& Timmins, 1937). It was found that the virulent strains killed all the mice in 10 days, or less, after intranasal inoculation of $400 \times 10^{6}$ bacilli or fewer. Post-mortem examination of the mice showed consolidation of the lungs, from which the strain was recovered.

The agglutinability of a strain was determined by titrating serial dilutions of rabbit Phase I pertussis antiserum against equal volumes of a formalin-killed suspension of the organisms. The final serum dilution that agglutinated the suspension was used as a measure of the agglutinability of the strain.

Inoculum. The organisms were subcultured only twice on Bordet-Gengou slopes before testing. Two-day-old cultures were washed off the slope with sterile saline, centrifuged and resuspended in sterile saline to an opacity corresponding to about $2000 \times 10^{6}$ organisms $/ \mathrm{ml}$. Of this suspension, $0.2 \mathrm{ml}$. was added to each $100 \mathrm{ml}$. of partially defined medium.

Partially defined medium. The liquid partially defined medium contained the constituents suggested by Cohen \& Wheeler(1945) dissolved in distilled water, and the $\mathrm{pH}$ was adjusted to $7 \cdot 6$. The medium was brought to the boil and a mucilage of soluble starch was poured in with continuous stirring to give a final concentration of $0.15 \%$. The medium was filtered whilst hot and allowed to cool, readjusted to $\mathrm{pH} \mathbf{7 \cdot 6}$, dispensed into the required containers and autoclaved at $20 \mathrm{lb}$. pressure for $\mathbf{2 0} \mathrm{min}$. At this stage it was clear, pale yellow and free from deposit.

Estimation of amount of bacterial growth. When $\boldsymbol{H}$. pertussis was incubated in this medium there was no visible growth for $\mathbf{2}$ or $\mathbf{3}$ days. Bacterial growth is commonly measured by direct count or turbidity, either by comparison of the suspension with a standard suspension or by use of a photoelectric absorptiometer. It was impossible to obtain a suitable counting chamber and the following method was therefore adopted. A known volume of a suitably diluted suspension of the organisms was smeared on a clean microscope slide and carefully dried by heat. The area of the smear was determined by projecting it on to a ground-glass screen and measuring the enlarged image with a planimeter, from 
which the area of the smear itself could be calculated. The organisms were then fixed with methanol, stained with carbol fuchsin and counted with a $\frac{1}{12}$ in. oil-immersion objective and an eyepiece graticule. The average number of organisms in 100 squares at different parts of the field was determined, the graticule having been calibrated against normal human erythrocytes (assumed diameter $7 \mu$.). The number of organisms/ml. was calculated from the formula:

Number of organisms $=$ Average per square $\times \frac{\text { Area of smear }}{\text { Area of square on graticule }}$

$$
\times \frac{1}{\text { Vol. of suspension }} \times \text { Dilution. }
$$

The method gave reproducible results with different concentrations of organisms. Table 1 shows the total count by the above method and the count estimated by opacity measurements with Brown's standard tubes (Burroughs Wellcome and Co.) of bacterial suspensions from a 14-day culture grown in the liquid semi-defined medium and from a $24 \mathrm{hr}$. culture on Bordet-Gengou medium. The ratio of the total count to the opacity count is approximately $1 \cdot 8$ for the liquid medium and $\mathbf{1 \cdot 3}$ for Bordet-Gengou medium. This difference is probably due to different optical properties resulting from morphological differences in the constituent cells.

Table 1. Relationship between opacity (by Brown's tubes) and total counts (by present method) in suspensions of Haemophilus pertussis

\begin{tabular}{|c|c|c|c|}
\hline \multirow[b]{2}{*}{ Medium and growth conditions } & \multicolumn{2}{|c|}{$\begin{array}{l}\text { Number of cells estimated by } \\
\left(\times 10^{6} / \mathrm{ml} .\right)\end{array}$} & \multirow[b]{2}{*}{$\boldsymbol{b} / \boldsymbol{a}$} \\
\hline & Opacity (a) & Total count $(b)$ & \\
\hline $\begin{array}{l}\text { Partially defined medium, 14-day culture } \\
\text { Organisms washed off and suspended } \\
\text { in saline }\end{array}$ & $\begin{array}{r}18,000 \\
3,500 \\
3,500\end{array}$ & $\begin{array}{r}32,000 \\
6,700 \\
5,800\end{array}$ & $\begin{array}{l}1 \cdot 8 \\
1 \cdot 9 \\
1 \cdot 7\end{array}$ \\
\hline & $\begin{array}{l}1,600 \\
1,600\end{array}$ & $\begin{array}{l}\mathbf{2 , 8 0 0} \\
\mathbf{3 , 0 0 0}\end{array}$ & $\begin{array}{l}1 \cdot 75 \\
1.85\end{array}$ \\
\hline $\begin{array}{l}\text { Bordet-Gengou medium, } 24 \mathrm{hr} \text {. culture } \\
\text { Organisms washed off and suspended } \\
\text { in saline }\end{array}$ & $\begin{array}{l}10,800 \\
10,800 \\
10,000\end{array}$ & $\begin{array}{l}11,000 \\
15,200 \\
12,600\end{array}$ & $\begin{array}{l}1 \cdot 0 \\
1 \cdot 4 \\
1 \cdot 2\end{array}$ \\
\hline & $\begin{array}{l}7,300 \\
7,300 \\
7,300\end{array}$ & $\begin{array}{r}7,700 \\
8,400 \\
11,000\end{array}$ & $\begin{array}{l}1 \cdot 1 \\
1 \cdot 2 \\
1 \cdot 5\end{array}$ \\
\hline & $\begin{array}{l}3,800 \\
\mathbf{3 , 8 0 0}\end{array}$ & $\begin{array}{l}4,100 \\
6,000\end{array}$ & $\begin{array}{l}1 \cdot 1 \\
1 \cdot 6\end{array}$ \\
\hline
\end{tabular}

As a final check on the bacterial count the total nitrogen contents of suspensions of different virulent strains were estimated (Table 2). Total nitrogen/1012 organisms remained constant, thus confirming that the nitrogen content of the bacterial cell could be used as an index of the number of organisms present. The opacity method, being the most convenient, was adopted. In all the tables the growth is expressed as the total count (i.e. opacity $\times$ the appropriate factor) in millions of organisms $/ \mathrm{ml}$. 
Table 2. Relationship between opacity and total Kjeldahl-nitrogen in suspensions of seven different strains of Haemophilus pertussis

\begin{tabular}{|c|c|c|c|}
\hline \multirow[b]{2}{*}{ Strain } & \multirow{2}{*}{$\begin{array}{l}\text { Number of organisms } \\
\text { estimated by opacity } \\
\qquad\left(\times 10^{6} / \mathrm{ml} .\right)\end{array}$} & \multicolumn{2}{|c|}{ Total N } \\
\hline & & (g./ml.) & (g. $/ 10^{12}$ cells) \\
\hline 1 & 137,000 & 0.0048 & $0 \cdot 035$ \\
\hline 2 & 114,000 & 0.0046 & 0.040 \\
\hline $\mathbf{3}$ & 114,000 & 0.0045 & 0.032 \\
\hline 4 & 91,000 & 0.0042 & 0.046 \\
\hline 5 & 57,000 & $0 \cdot 0023$ & 0.040 \\
\hline 6 & 34,000 & 0.0012 & 0.035 \\
\hline 7 & 28,000 & 0.0012 & 0.042 \\
\hline
\end{tabular}

\section{THE PHYSICAL CONDITIONS FOR THE GROWTH OF HAEMOPHILUS PERTUSSIS}

Size of inoculum. The inoculum was varied from 4.5 to $350 \times 10^{6}$ organisms/ $\mathrm{ml}$. We found that even a 70-fold increase in size of the initial inoculum had little effect on the lag period or growth of the organisms (cf. Fisher, 1948).

Effect of $\mathrm{pH}$. The partially defined medium was divided into several portions, which were adjusted to different $\mathrm{pH}$ values over the range $6 \cdot 6-8 \cdot 6$. These samples of medium were then dispensed in $100 \mathrm{ml}$. amounts in $10 \mathrm{oz}$. medicine bottles and sterilized. There was no change in the $\mathrm{pH}$ on autoclaving. The media were inoculated with various virulent strains and incubated at $37^{\circ}$ for 9 days.

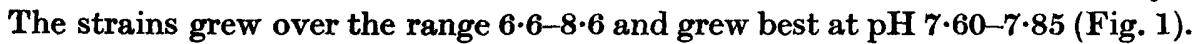
In all succeeding experiments with the partially defined medium the initial $\mathrm{pH}$ was $7 \cdot 6$.

\section{The gaseous requirements for growth in liquid partially defined medium}

Nitrogen. The partially defined medium was dispensed in $800 \mathrm{ml}$. amounts in 21. conical flasks, which were autoclaved and incubated. Oxygen-free nitrogen was bubbled through concentrated sulphuric acid and then distilled water, passed through sterile air-filters, and slowly bubbled through the medium in two flasks and above the medium in a third flask; a fourth flask, without passage of gas, served as control. The media were inoculated with virulent organisms and incubated for 5 days; there was no growth in the media through which the nitrogen was bubbled or over which the nitrogen was passed. The count in the control medium was $3600 \times 10^{6}$ organisms $/ \mathrm{ml}$. It appeared that the nitrogen was giving rise to unfavourable anaerobic conditions.

Air. The above experiment was repeated, the nitrogen being replaced by washed and filtered air, using a virulent and an avirulent strain. The growth of the avirulent strain was greater in the aerated medium than in the unaerated medium (Table 3). The virulent strain failed to grow in medium through which the air was passed. After 4 days' incubation a sample seeded on BordetGengou medium proved to be sterile, indicating that even the original inoculum was dead. This result was regularly experienced, even with marked variations in the rate of aeration. The unaerated control medium showed good 
Table 3. Growth of an avirulent strain of Haemophilus pertussis with different conditions of aeration

\begin{tabular}{lccccc} 
& \multicolumn{4}{c}{$\begin{array}{c}\text { Growth after (days) } \\
\text { (cells } \times 10^{6} / \mathbf{m l} \text { ) }\end{array}$} \\
Conditions of growth & $\overbrace{1}$ & 5 & 11 & 13 \\
aerated medium & 700 & $\mathbf{2 , 0 0 0}$ & $\mathbf{3 , 6 0 0}$ & $\mathbf{3 , 6 0 0}$ \\
assed over medium surface & 400 & 1,300 & $\mathbf{3 , 6 0 0}$ & $\mathbf{3 , 6 0 0}$ \\
passed through medium & $\mathbf{7 0 0}$ & $\mathbf{3 , 6 0 0}$ & 10,000 & 10,800
\end{tabular}

growth on the fourth day. It was clear that aeration increased the growth of an avirulent but inhibited that of a virulent strain.

Carbon dioxide. The organisms were grown in Winchester quart bottles, the space above the medium being filled with different mixtures of air and carbon dioxide. Growth occurred over the range of carbon dioxide concentration 0.03-25 \% and was optimal between 0.03 and $10 \%$ carbon dioxide. With more than $10 \%$ carbon dioxide the growth after 12 days' incubation decreased rapidly as the carbon dioxide concentration increased. The $\mathrm{pH}$ of the medium also fell, which probably accounts for the inhibition of growth.

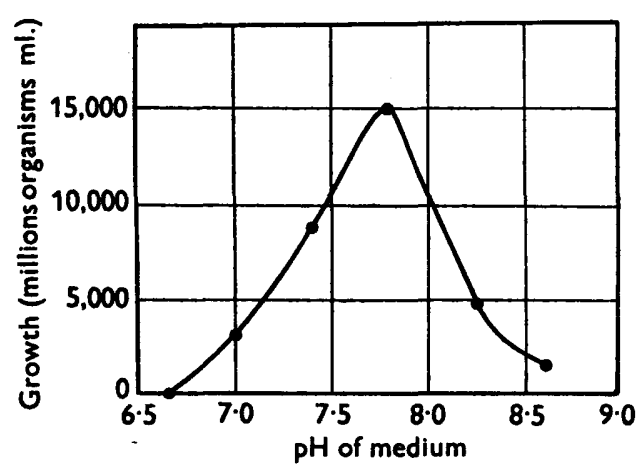

Fig. 1

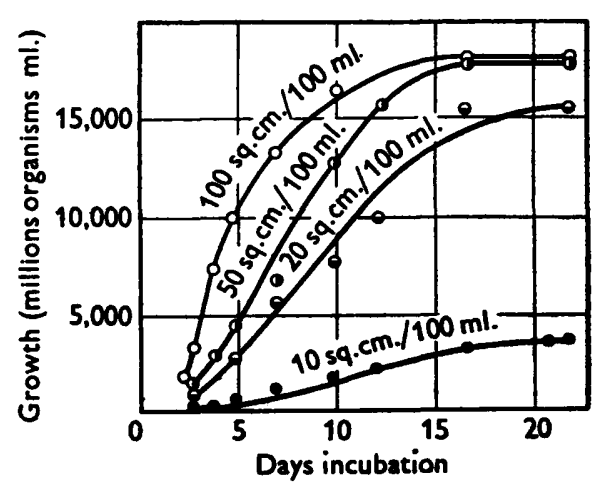

Fig. 2

Fig. 1. Variation of the growth of $H$. pertussis with the initial pH of the medium.

Fig. 2. Growth of $\boldsymbol{H}$. pertussis in $10 \mathrm{oz}$. medical bottles containing different amounts of medium.

Mechanical agitation. Farrell \& Taylor (1945) stated that mechanical agitation of the medium during incubation considerably decreased the period of incubation. We tried two methods of agitation: stirring the culture by means of an electric motor and rotating the culture container at an angle of forty degrees from the vertical. The method of mechanical agitation was immaterial; it always increased the growth of avirulent strains of $\boldsymbol{H}$. pertussis and inhibited that of virulent strains.

Varying the surface/volume ratio. Cohen \& Wheeler (1945) showed that the best growth was obtained in liquid medium dispensed into vessels so that there 
was a very shallow layer of medium having a relatively large surface area, i.e. when there was a high surface/volume ratio. We confirmed this with vessels of various shapes and sizes. The medium was dispensed and sterilized in Winchester quart bottles, mould-culture flasks and $10 \mathrm{oz}$. flat medicine bottles to give surface/volume ratios ranging from 5 to $400 \mathrm{sq} . \mathrm{cm} . / 100 \mathrm{ml}$. of medium, i.e.

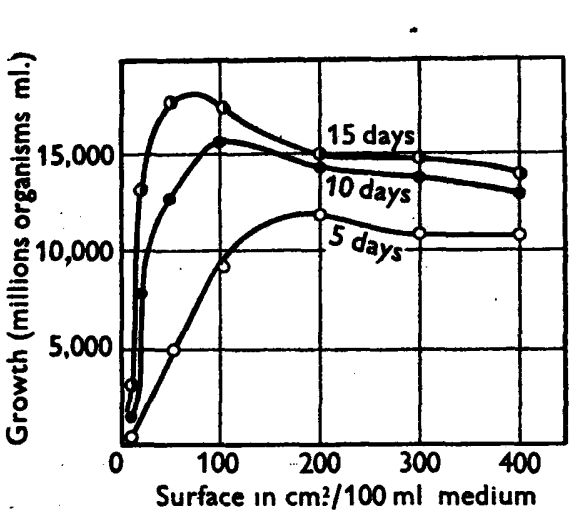

Fig. 3

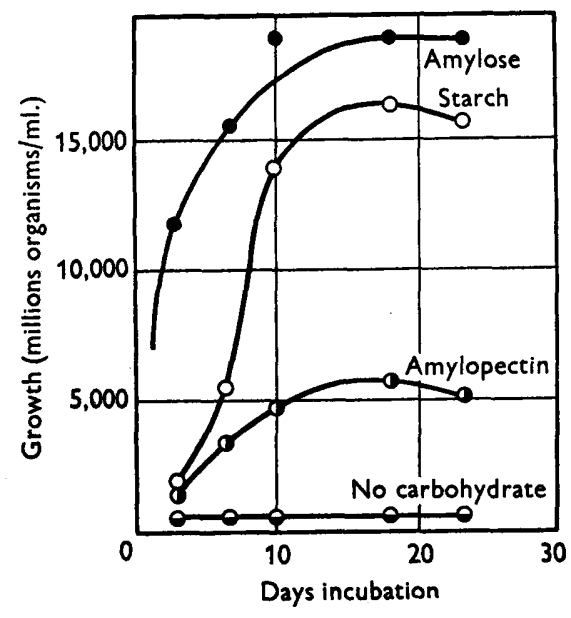

Fig. 4

Fig. 3. Variation of growth with the surface area after different times of incubation.

Fig. 4. Growth of $H$. pertussis in media containing different starch fractions.

ratios from 0.05 to 4 . These were inoculated with a virulent strain and incubated at $87^{\circ}$. Fig. 2 shows the mean growths for different surface/volume ratios plotted against the period of incubation. As the surface/volume ratio increased, so did the initial growth. The maximum growth obtained with the larger surface/volume ratios was the same, but the time required to reach this value decreased with increasing values of this ratio. Fig. 3 shows growth after 5, 10 and 15 days' incubation plotted against different surface/volume ratios. The optimal surface/volume ratio decreased as the period of incubation increased. Surface/volume ratios in excess of the optimal, for any given period of incubation, appeared to be slightly inhibitory. This is consistent with the inhibitory effect of aeration. In another experiment a virulent strain was grown in $10 \mathrm{oz}$. medicine bottles containing varying amounts of medium; shaking the bottles for $5 \mathrm{~min}$. each day inhibited the growth only when the surface/volume ratio was not optimal. Shaking bottles containing the optimal amount of medium had no effect on the growth. Growth under optimal conditions was diffuse, whereas under other conditions the growth occurred as a pellicle on the surface of the medium. 
THE NUTRITIONAL REQUIREMENTS OF HAEMOPHILUS PERTUSSIS

The main constituents of the medium were carbohydrate, amino-acids, yeast dialysate and certain inorganic salts.

\section{Carbohydrate requirement}

Previous workers have stressed that starch is essential for the growth of $\boldsymbol{H}$. pertussis. Hornibrook (1939) deduced the utilization of starch by the organisms from the iodine colour reactions of the medium before and after growth. Pollock (1949) showed that, during the growth of a 'modified' strain, unsaturated fatty acids were produced and he suggested that they were adsorbed on the starch. Schoch \& Williams (1944) showed that the adsorption of unsaturated fatty acids on starch caused the normally blue iodine-starch complex to assume a brownish red colour. It may well be that $H$. pertussis produces fatty acids and that the change in colour of the iodine-starch complex is not due to utilization at all, but to adsorption of fatty acids.

Starch. The type of starch appeared to be immaterial; after 16 days' incubation the counts in media containing soluble, maize or potato starch were respectively $15,500,13,500$ and $16,000 \times 10^{6}$ organisms $/ \mathrm{ml}$. We investigated the different starch requirements of twenty strains of $H$. pertussis and two strains of $\boldsymbol{H}$. parapertussis. Media were made up containing the usual amount of starch $(0.15 \%)$ or without starch; three lots of each medium were inoculated. Virulent strains of $\boldsymbol{H}$. pertussis grew only in the presence of starch, whereas avirulent strains and the two strains of $H$. parapertussis grew as readily without starch (Table 4). Agglutinability by rabbit Phase I pertussis antiserum was high for the virulent strains, low for organisms growing readily in the absence of starch and nil for avirulent strains. There thus seems to be a correlation between virulence, agglutinability and starch requirements, in that a virulent, agglutinable strain of $\boldsymbol{H}$. pertussis will grow only in the presence of starch, while an avirulent, poorly agglutinable strain grows readily in its absence. $\boldsymbol{H}$. parapertussis formed a diffuse turbidity in the culture medium and coloured it dark-brown, whereas $\boldsymbol{H}$. pertussis grew with a pellicle on the surface and did not darken the medium.

Concentration of starch. Table 5 shows the effect of simultaneously varying the concentrations of starch and casein hydrolysate in the partially defined medium. Other virulent strains of $\boldsymbol{H}$. pertussis behaved similarly. From these results we conclude that starch is essential for the growth of virulent strains but that concentrations of starch above $0.15 \%$ do not improve growth. In this we differ considerably from Fisher (1948), who stated that the optimum concentration was 1.5 to $2.0 \%$.

Replacement of starch. Hornibrook (1939) stated that it was possible to replace the starch in the medium by another polysaccharide, $\beta$-dextrin, but that substances such as glycogen, saliva-hydrolysed starch, glucose, lactose, maltose, laevoglucosan, gum-acacia, mucin and agar could not do so. We found that starch could be replaced only by one of its constituents, namely, amylose; substances such as dextrin, glycogen, Cori ester, dextran, salicin and amylo- 
Table 4. Growth of different strains of Haemophilus pertussis in media with or without starch

\begin{tabular}{|c|c|c|c|c|c|c|c|}
\hline \multirow[b]{3}{*}{ Strain } & \multirow{3}{*}{$\begin{array}{l}\text { Virulence } \\
\text { after } 0, \\
4 \text { and } 12 \\
\text { days growth }\end{array}$} & \multicolumn{2}{|c|}{ Agglutination titre } & \multicolumn{4}{|c|}{ Growth (cells $\times 10^{6} / \mathrm{ml}$.) after (days) } \\
\hline & & \multirow{2}{*}{$\begin{array}{l}12 \text { days } \\
\text { in liquid } \\
\text { media }\end{array}$} & \multirow{2}{*}{$\begin{array}{l}2 \text { days on } \\
\text { Bordet- } \\
\text { Gengou }\end{array}$} & \multicolumn{2}{|c|}{4} & \multicolumn{2}{|c|}{12} \\
\hline & & & & Starch & No starch & Starch & No starch \\
\hline $\mathbf{8 2} \mathbf{E}$ & $+t+$ & $1 / 10,000$ & $1 / 16,000$ & 1,200 & $\mathbf{0}$ & 20,000 & 2,000 \\
\hline 83E & $+t+$ & $1 / 10,000$ & $1 / 16,000$ & 2,200 & $\mathbf{0}$ & 17,000 & $\mathbf{0}$ \\
\hline $102 \mathrm{E}$ & $+t+$ & $1 / 10,000$ & $1 / 2,000$ & $\mathbf{3 , 5 0 0}$ & $\mathbf{0}$ & 18,000 & $\mathbf{0}$ \\
\hline $104 \mathrm{E}$ & + & $1 / 10,000$ & $1 / 16,000$ & 1,500 & 1,600 & 17,500 & 14,500 \\
\hline $105 \mathrm{E}$ & - & $1 / 500$ & $1 / 1,600$ & 1,500 & 1,200 & 18,000 & 18,000 \\
\hline $146 \mathrm{E}$ & - & $1 / 500$ & $1 / 1,000$ & 1,200 & 1,000 & 7,200 & 6,500 \\
\hline $154 \mathrm{E}$ & - & $1 / 500$ & $1 / 1,000$ & 1,200 & 2,000 & 7,200 & 14,000 \\
\hline $167 \mathrm{E}$ & - & $1 / 500$ & $1 / 1,000$ & 1,200 & 2,000 & 7,200 & 11,000 \\
\hline $169 \mathrm{E}$ & H. parapertussis & $1 / 2,500$ & $1 / 500$ & $\mathbf{3 , 5 0 0}$ & 3,600 & 20,000 & 20,000 \\
\hline $191 \mathrm{E}$ & $++t$ & $1 / 10,000$ & $1 / 20,000$ & 1,200 & 0 & 18,000 & 0 \\
\hline $192 \mathrm{E}$ & $+t+$ & $1 / 10,000$ & $1 / 16,000$ & 2,000 & $\mathbf{0}$ & 20,000 & $\mathbf{0}$ \\
\hline $193 \mathrm{E}$ & +++ & $1 / 10,000$ & $1 / 16,000$ & 700 & $\mathbf{0}$ & 17,000 & $\mathbf{0}$ \\
\hline $196 \mathrm{E}$ & +++ & $1 / 5,000$ & $1 / 16,000$ & 1,000 & $\mathbf{0}$ & 17,000 & $\mathbf{0}$ \\
\hline $197 \mathrm{E}$ & $++t$ & $1 / 10,000$ & $1 / 16,000$ & 1,200 & 0 & 11,000 & $\mathbf{0}$ \\
\hline $199 \mathrm{E}$ & $++t$ & $1 / 10,000$ & $1 / 8,000$ & 1,000 & o & 17,000 & $\mathbf{0}$ \\
\hline $203 \mathrm{E}$ & + & $1 / 10,000$ & $1 / 4,000$ & 1,200 & 100 & 18,000 & 7,200 \\
\hline $204 E$ & $+t+$ & $1 / 5,000$ & $1 / 8,000$ & 1,200 & 0 & 10,000 & 0 \\
\hline $207 \mathrm{E}$ & H. parapertussis & $1 / 5,000$ & $1 / 250$ & $\mathbf{3 , 5 0 0}$ & 4,200 & 20,000 & 19,000 \\
\hline $209 \mathrm{E}$ & $+t+$ & $1 / 10,000$ & $1 / 16,000$ & 1,500 & 0 & 18,000 & 0 \\
\hline $210 E$ & +++ & $1 / 10,000$ & $1 / 16,000$ & 1,000 & $\mathbf{0}$ & 14,500 & 1,800 \\
\hline
\end{tabular}

$+=50 \%$; and $+++=$ all mice dead in 10 days with $200 \times 10^{6}$ organisms.

Table 5. The growth of a virulent strain of Haemophilus pertussis in media containing different concentrations of casein hydrolysate and starch

\begin{tabular}{ccccc} 
& \multicolumn{4}{c}{ Starch concentration (\%) } \\
Casein (\%) & $\begin{array}{c}0 \cdot 15 \\
\mathbf{0 \cdot 0 3}\end{array}$ & $\begin{array}{c}0 \cdot 5 \\
\text { Growth }\left(\text { cells } \times 10^{\circ} / \mathrm{ml} \text { ) } \text { on 14th day }\right.\end{array}$ & $1 \cdot 0$ \\
1 & - & 5,500 & 6,000 & 7,300 \\
4 & $\mathbf{8 , 6 0 0}$ & 17,200 & - & - \\
4 & - & 12,000 & 13,000 & 13,600 \\
8 & - & 15,800 & 15,800 & 15,800 \\
12 & - & 5,900 & 6,600 & 6,000 \\
16 & - & 5,700 & 5,900 & 5,900
\end{tabular}

pectin allowed only limited growth. Amylose and amylopectin fractions prepared from potato starch (Haworth, Peat \& Sagroth, 1946) were tested at a concentration of $0.15 \%$ in place of the potato starch. In the initial stages of incubation, growth was more rapid in the medium containing the amylose (Fig. 4); there was, however, little difference between the final stationary populations in the amylose and the starch media. Amylopectin, on the other hand, permitted only limited growth.

The experiment was repeated with soluble starch and the corresponding amylose and amylopectin, and with a mixture of amylose and amylopectin in the same proportions as they occur in starch (Table 6). Again the best and 
most rapid growth occurred in the medium containing amylose in place of the starch. There was no difference between the growth in the starch medium and the one containing a mixture of 1 part of amylose and 4 parts of amylopectin. The growth of the organisms in the different starch fractions did not affect agglutinability on the ninth day.

Table 6. Growth of a virulent strain of Haemophilus pertussis in media containing different starch fractions

\begin{tabular}{lrrrr} 
& \multicolumn{3}{c}{ Growth (cells $\times 10^{\circ} / \mathrm{ml}$.) after (days) } \\
\cline { 2 - 5 } & \multicolumn{1}{c}{4} & \multicolumn{1}{c}{$\boldsymbol{1}$} & 16 & \multicolumn{1}{c}{} \\
Soluble starch & $\mathbf{2 , 2 0 0}$ & 15,000 & 15,500 & 14,000 \\
Soluble amylose & 11,000 & 18,000 & 18,500 & 17,500 \\
Soluble amylopectin & 7,000 & 9,000 & 9,200 & 7,400 \\
Mixture of amylose (1 part) & 2,300 & 11,500 & 13,000 & 12,200 \\
and amylopectin (4 parts) & & & &
\end{tabular}

When starch was replaced by the following substances $(0 \cdot 15 \%)$ the relative growths of a virulent strain at the 9th day, expressed as percentage of growth with starch, were: amylose (135), mannitol (46), glycogen (38), amylopectin (35), dextrin (32), Cori ester (24), salicin (23), dextran (23), sucrose (18), maltose (16), lactose (16), gum tragacanth, gum acacia or gum arabic (6), glucose (5) and apple pectin, agar or agar pectin (0).

Many organisms produce starch or starch-like substances from Cori ester (Hehre, Carlson \& Neill, 1947), but neither a virulent nor an avirulent strain of $H$. pertussis formed starch or dextrin as shown by the iodine test.

Adsorbent effect of starch. In a study of the growth of a strain of $H$. pertussis, Pollock (1947) showed that the blood in the Bordet-Gengou medium could be replaced by charcoal and that charcoal could replace the starch in a semidefined medium. There thus appeared to be two possible functions of the starch required for the growth of a virulent strain : it might act either as an adsorbent for toxic substances or as. a source of carbohydrate.

These hypotheses were tested with virulent and avirulent strains. If the starch is acting primarily as an adsorbent then it should be possible to replace it by other absorbents. It was found that a virulent strain grew in a starchfree medium provided that charcoal was present.

The medium without starch, at $\mathrm{pH} 7 \cdot 6$, was dispensed in $250 \mathrm{ml}$. amounts in 11. conical flasks and in $100 \mathrm{ml}$. amounts in $10 \mathrm{oz}$. flat medicine bottles. Charcoal (acid-washed Sutcliffe Speakman No. 5) was added to give $0 \cdot 1$ and $0.4 \%(w / v)$ respectively. In addition, an equivalent amount of charcoal was suspended in saline, tied up in a cellophan bag (grade 300, McMillan and Marshall) and put in the medium. As a control a starch solution was enclosed in a cellophan bag and placed in another flask of medium. The medium containing charcoal supported growth, but the final stationary population was less than that in the medium containing starch. Growth in the medium in which the charcoal was enclosed in a cellophan bag was almost equal to that in the complete medium. Organisms grown in the presence of starch were highly agglutin- 
able and showed no change in morphology. From unpublished experiments, however, it appears that starch may not act solely as an adsorbent of toxic products. The following substances (at $0.1 \%, \mathrm{w} / \mathrm{v}$ ) could not replace starch: egg-albumin, alumina, silica gel, gelatin, agar.

\section{Amino-acid requirements}

Casein hydrolysate. The amino-acids required for growth are supplied by a casein hydrolysate, which was prepared by refluxing technical grade lactic casein with $6 \mathrm{~N}-\mathrm{HCl}$ for $18 \mathrm{hr}$. and then removing as much $\mathrm{HCl}$ as possible by vacuum distillation. The hydrolysate was then diluted with water and partially decolorized by boiling with charcoal, filtered through kieselguhr and adjusted to $\mathrm{pH} \mathrm{6.7}$ with caustic soda; the insoluble tyrosine was removed by filtration, and $40 \mathrm{ml}$. of this hydrolysate were included in each litre of the medium, giving a total amino nitrogen concentration of about $1 \mathrm{mg} . / \mathrm{ml}$.

The casein hydrolysate usually used in the preparation of the semi-defined medium contained $16 \%$ sodium chloride. It was necessary to decrease this concentration before high casein contents could be tested, because a high salt content is inhibitory to the growth of most micro-organisms. The casein hydrolysate was passed through an ion-exchange resin, which decreased the salt content to $5 \cdot 9 \%$. Various concentrations of effluent were added to the medium, the final $\mathrm{NaCl}$ content being adjusted to $0.89 \%$. Growth on the 14th day was greatest with a casein concentration of about $7 \%$; with higher concentrations growth was inhibited.

'Vitamin-free' casein hydrolysate. The standard casein hydrolysate was compared in growth-promoting activity with 'vitamin-free' casein hydrolysed by hydrochloric acid, sulphuric acid or barium hydroxide. Media containing either acid- or alkaline-hydrolysed casein differed little. The apparent difference between the 'technical' and the 'vitamin-free' casein was further studied (Table 7). Solid 'technical' casein was refluxed for $12 \mathrm{hr}$. with ethanol to remove residual fat and traces of certain vitamins. The casein was filtered off, dried and hydrolysed. Media were made up containing this 'vitamin-free' casein hydrolysate or the original technical casein hydrolysate. Initial growth was slightly greater in the latter but the final bacterial count was the same in both media. Further, the ethanolic extract of the casein was slightly inhibitory, owing perhaps to the fatty substances it contained.

Table 7. Effect of different casein hydrolysates on growth of a virulent strain of Haemophilus pertussis

(Size of inoculum: $400 \times 10^{6}$ cells $/ 100 \mathrm{ml}$. of medium.)

\begin{tabular}{|c|c|c|c|c|}
\hline \multirow[b]{2}{*}{ Casein } & \multirow[b]{2}{*}{$\begin{array}{l}\text { Method of } \\
\text { hydrolysis }\end{array}$} & \multirow[b]{2}{*}{$\begin{array}{l}\text { Charcoal } \\
\text { treatment }\end{array}$} & \multicolumn{2}{|c|}{$\begin{array}{c}\text { Growth (cells } \times 10^{6} / \mathrm{ml} \text {.) } \\
\text { after (days) }\end{array}$} \\
\hline & & & 7 & 10 \\
\hline Technical & $6 \mathrm{~N}-\mathrm{HCl}$ & Yes & 11,000 & 18,500 \\
\hline Vitamin-free & $\mathrm{Ba}(\mathrm{OH})_{2}$ & No & $\mathbf{3 , 6 0 0}$ & 10,000 \\
\hline Vitamin-free & $6 \mathrm{~N}-\mathrm{HCl}$ & Yes & 6,300 & 10,000 \\
\hline Vitamin-free & $6 \mathrm{~N}-\mathrm{HCl}$ & No & 5,400 & 12,500 \\
\hline Technical & $\mathrm{H}_{2} \mathrm{SO}_{4}$ & No & 4,500 & 10,500 \\
\hline
\end{tabular}


Purification of the casein hydrolysate. Casein acid-hydrolysate was purified by various methods (Table 8). Boiling the casein hydrolysate with acid-washed charcoal in alkaline solution removed some of the growth-promoting substances; similar charcoal treatment in acid solution removed less. Hydrolysates filtered through kieselguhr or paper pulp gave as good growth as did untreated ones. This method of treatment, however, gave a very dark brown medium. Boiling the complete medium with acid-treated charcoal, readjusting the $\mathbf{p H}$ to $\mathbf{7 \cdot 6}$ and then filtering gave a medium that supported little, if any, growth.

Table 8. Effect of charcoal (C) treatment of casein hydrolysate on growth of virulent strain of Haemophilus pertussis

\begin{tabular}{|c|c|c|c|c|c|c|}
\hline \multirow[b]{2}{*}{ Treatment } & \multirow{2}{*}{$\begin{array}{l}\mathrm{pH} \text { of } \\
\text { medium }\end{array}$} & \multicolumn{5}{|c|}{ Growth (cells $\times 10^{6} / \mathrm{ml}$.) after (days) } \\
\hline & & 2 & $\mathbf{5}$ & 9 & 12 & 21 \\
\hline Filtered through kieselguhr & $7 \cdot 52$ & $\mathbf{0}$ & 250 & 6,300 & 11,000 & 11,500 \\
\hline Filtered through paper pulp & $\mathbf{7 \cdot 5 7}$ & 300 & $6, \mathbf{3 0 0}$ & 6,800 & 11,500 & 11,500 \\
\hline $\begin{array}{l}\text { Boiled once with } \mathbf{C} \text { at } \mathrm{pH} 4 \text {, } \\
\text { filtered }\end{array}$ & $7 \cdot 53$ & 350 & 4,500 & 7,200 & 11,000 & 11,000 \\
\hline $\begin{array}{l}\text { Boiled twice with } \mathrm{C} \text { at } \mathrm{pH} 4 \text {, } \\
\text { filtered }\end{array}$ & $7 \cdot 50$ & $\mathbf{3 5 0}$ & 6,300 & 7,400 & 13,000 & 15,500 \\
\hline $\begin{array}{l}\text { Boiled once with } \mathrm{C} \text { at } \mathrm{pH} 4 \text {, } \\
\text { neutralized and boiled with } \\
\mathrm{C} \text { at pH } 7\end{array}$ & $7 \cdot 60$ & 200 & 270 & 1,800 & 3,600 & $\mathbf{3 , 2 0 0}$ \\
\hline $\begin{array}{l}\text { Neutralized and boiled once } \\
\text { with } \mathrm{C} \text { at pH } 7\end{array}$ & $7 \cdot 60$ & 200 & 1,800 & 5,400 & 10,000 & 6,500 \\
\hline $\begin{array}{l}\text { Neutralized boiled twice with } \\
\text { C at pH } 7\end{array}$ & $7 \cdot 48$ & 200 & $\mathbf{4 , 2 0 0}$ & $\mathbf{3 , 0 0 0}$ & 6,800 & $\mathbf{5 , 5 0 0}$ \\
\hline
\end{tabular}

The results in italics are for media containing untreated casein hydrolysate.

Utilization of amino-acids during growth. Three strains of $\boldsymbol{H}$. pertussis were grown in the standard medium, the growth was measured after different periods of incubation. At the end of 15 days' incubation the cells were removed from the medium by centrifuging, the supernatant was preserved under toluene, and its amino-acids were assayed by paper chromatography (Dent, 1948; Consden, Gordon \& Martin, 1944). PI. 1 shows the developed chromatograms obtained with $0.022 \mathrm{ml}$. of supernatant fluids from cultures of a virulent (83E) and an avirulent strain (154 E) on Whatman No. 4 filter-paper. Aspartic acid, glutamic acid, serine, threonine, glycine and alanine were utilized to a greater or lesser extent, depending on the period of incubation. Proline (which cannot be seen in the photograph, because the proline-ninhydrin complex is yellow) was completely used after 15 days. The size and intensity of the spots from the culture fluids were compared visually with those of the same spots from the uninoculated control solution, to give a rough measure of the amounts of amino-acids utilized (Table 9). Table 9 also records the approximate amino-acid contents of the culture fluids estimated by the methods of Pope \& Stevens (1937). Fig. 5 shows the growth and the corresponding curve of total amino-acid utilization for a virulent strain. This amino-acid utilization suggested that it might be advantageous to fortify the medium with amino-acids or with more casein hydrolysate, but the addition of aspartic acid, glutamic acid, serine and glycine neither shortened the lag nor increased the stationary population. 


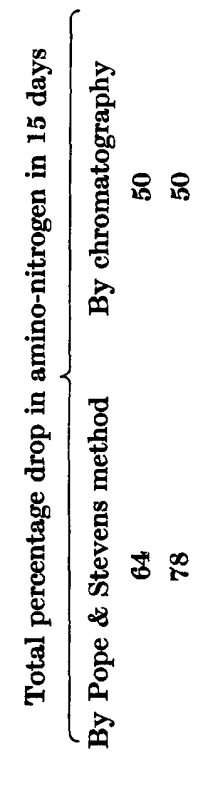

5

总

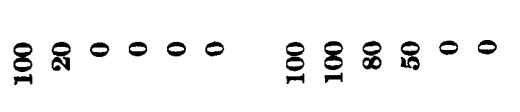

莺 $800000 \% 80000$

.

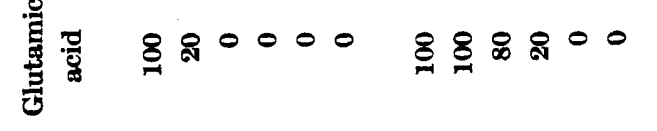

要

$\&$ \&용ำ

$\$ 8.000$

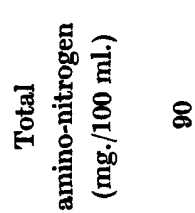

용 8

ส

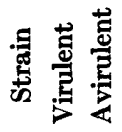

$\stackrel{0}{\frac{0}{0}}$

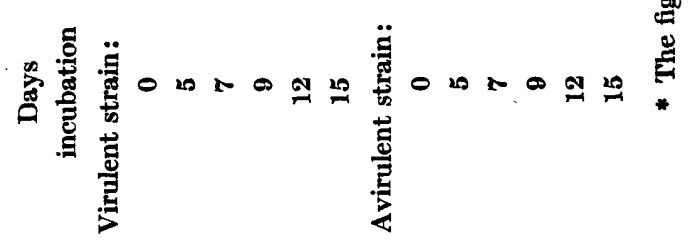


Other nutritional requirements of Haemophilus pertussis

Yeast dialysate. Yeast extract increases growth in liquid partially defined medium (Hornibrook, 1939). We found that a yeast infusion had the same growthpromoting properties as a yeast dialysate from the same amount. It thus appears that during dialysis in distilled water at $80^{\circ}$ for $18 \mathrm{hr}$. the necessary growth factors pass into the dialysate, and are not heat-labile. All media used contained yeast dialysate, which was stored under toluene at $5^{\circ}$ until required for use. A virulent strain of $\boldsymbol{H}$. pertussis did not grow in medium without yeast dialysate, but grew luxuriantly when a small amount was added. A twentyfold increase in concentration did not improve growth further.

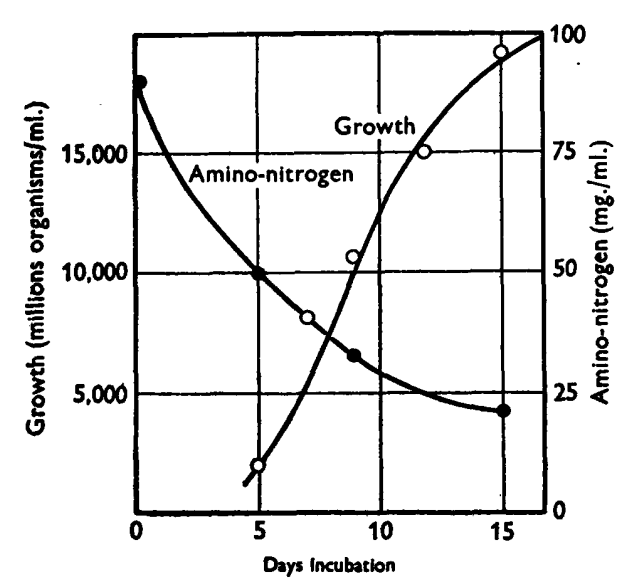

Fig. 5

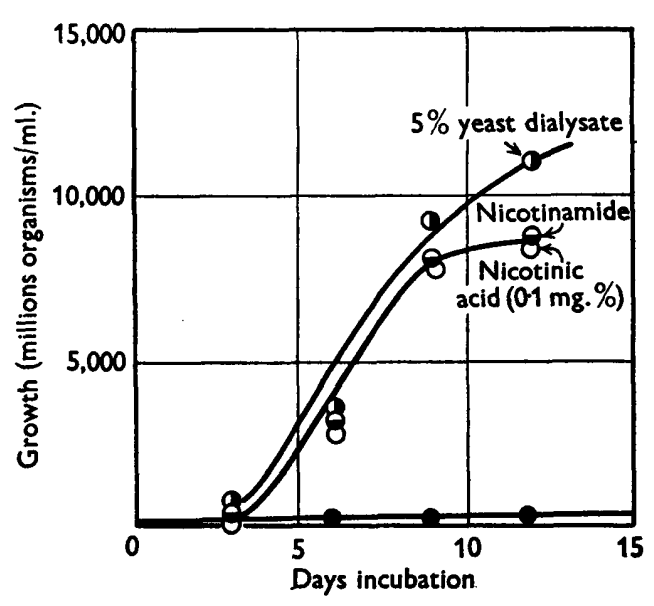

Fig. 6

Fig. 5. Growth of $H$. pertussis and the utilization of amino-nitrogen in the medium.

Fig. 6. Growth of $H$. pertussis in media in which the yeast dialysate is replaced by nicotinamide and nicotinic acid.

Replacement of yeast dialysate. Hornibrook (1939) reported that yeast dialysate in the partially defined medium could be replaced by nicotinic acid or nicotinamide. $\boldsymbol{H}$. pertussis grew readily in the presence of $0.1 \mathrm{mg}$. nicotinic acid or nicotinamide $/ \mathbf{1 0 0} \mathrm{ml}$., in place of yeast dialysate, but the final bacterial population was decreased by about $20 \%$ (Fig. 6). A preparation of cozymase (Sumner, Krishman \& Sisher, 1947) at 0.06 mg./100 ml., supported the growth better than did nicotinamide. Weight for weight the preparation of cozymase was more active than the nicotinamide or nicotinic acid, suggesting that the organisms synthesize cozymase from nicotinic acid.

Organic sulphur. Hornibrook (1939) stated that organic sulphur is essential for the growth of the organism. Yeast dialysate contains organic sulphur in methionine and cystine (Diemain \& Fresenius, 1947) and must be omitted from the medium for a study of the sulphur requirements of $\boldsymbol{H}$. pertussis. In the medium used yeast dialysate was replaced by nicotinamide, and cystine, cysteine, methionine or glutathione added as required. We confirmed that a 
virulent strain required a sulphur-containing amino-acid for growth (Table 10), usually supplied in yeast dialysate and by cysteine. When yeast dialysate is replaced by nicotinamide, cysteine, cystine or glutathione must be added for growth to occur. Methionine cannot supply the organic sulphur required.

Table 10. Growth of Haemophilus pertussis in media containing different sulphur-containing amino-acids

$\quad \begin{aligned} & \text { Yeast or } \\ & \text { nicotinamide } \\ & \quad \text { added }\end{aligned}$
Yeast
Nil
Yeast
Nicotinamide
Nicotinamide
Nicotinamide
Nicotinamide
Nicotinamide

$\begin{aligned} & \text { Source of } \\ & \text { sulphur }\end{aligned}$
Cysteine
Nil
Nil
Cystine
Cysteine
Methionine
Glutathione
Nil

\begin{tabular}{crrr}
\multicolumn{4}{c}{ Growth (cells $\times 10^{6} / \mathbf{m l}$.) after (days) } \\
\hline 3 & \multicolumn{1}{c}{7} & \multicolumn{1}{c}{11} & \multicolumn{1}{c}{14} \\
1,800 & 12,000 & 13,000 & 15,000 \\
2,000 & 2,000 & 2,000 & 2,000 \\
1,800 & 12,000 & 13,000 & 15,000 \\
1,400 & 7,200 & 13,000 & 13,000 \\
2,000 & 5,200 & 12,000 & 13,000 \\
2,000 & 3,200 & 4,100 & 7,000 \\
2,000 & 5,200 & 11,000 & 14,500 \\
2,000 & 2,000 & 2,000 & 2,000
\end{tabular}

\section{CONCLUSION}

The difference between virulent and avirulent strains of the same bacterial species has a practical as well as a theoretical interest, especially for those concerned with the preparation of prophylactic and therapeutic vaccines and antisera. Understanding of the fundamental biochemical differences that ultimately determine the intra-species differences in virulence is likely to be forwarded by a study of all differences in physical, chemical and biological properties that can be demonstrated between the two extreme types of strain.

In earlier papers (Ungar \& Muggleton, 1948, 1949) we recorded different 'solubilities' of virulent and avirulent strains of $\boldsymbol{H}$. pertussis in caustic soda and bile salt solutions, which completely 'dissolve' the virulent but not the avirulent strains. There was a similar contrast between the strains on treatment with aluminium phosphate precipitated in situ; there was simultaneous precipitation of virulent, but not of avirulent, strains.

We have now demonstrated clearly two main nutritional differences in their relative needs for starch and amino-acids; there are also clear-cut differences between the effects of other environmental conditions such as supply of oxygen and $\mathrm{pH}$. How far differences of this kind are related, and in what way, to the differences in physical properties recorded in our earlier papers and to differences in virulence, it is not yet possible to say, but it seems likely that they all depend on some fundamental biochemical divergence.

\section{REFERENCES}

Bordet, J. \& Gengou, O. (1906). Le microbe de la coqueluche. Ann. Inst. Pasteur, 20, 731 .

Burnet, F. M. \& Trmmins, C. (1937). Experimental infection with Haemophilus pertussis in the mouse by intranasal infection. Brit. J. exp. Path. 18, 83.

Cohen, S. \& Wheeler, M. (1945). Pertussis vaccine prepared with Phase I cultures in fluid medium. Report of the Division of Laboratories and Research N.Y. State Department of Health, p. 39. 
Journal of General Microbiology, Vol. 4, No. 3

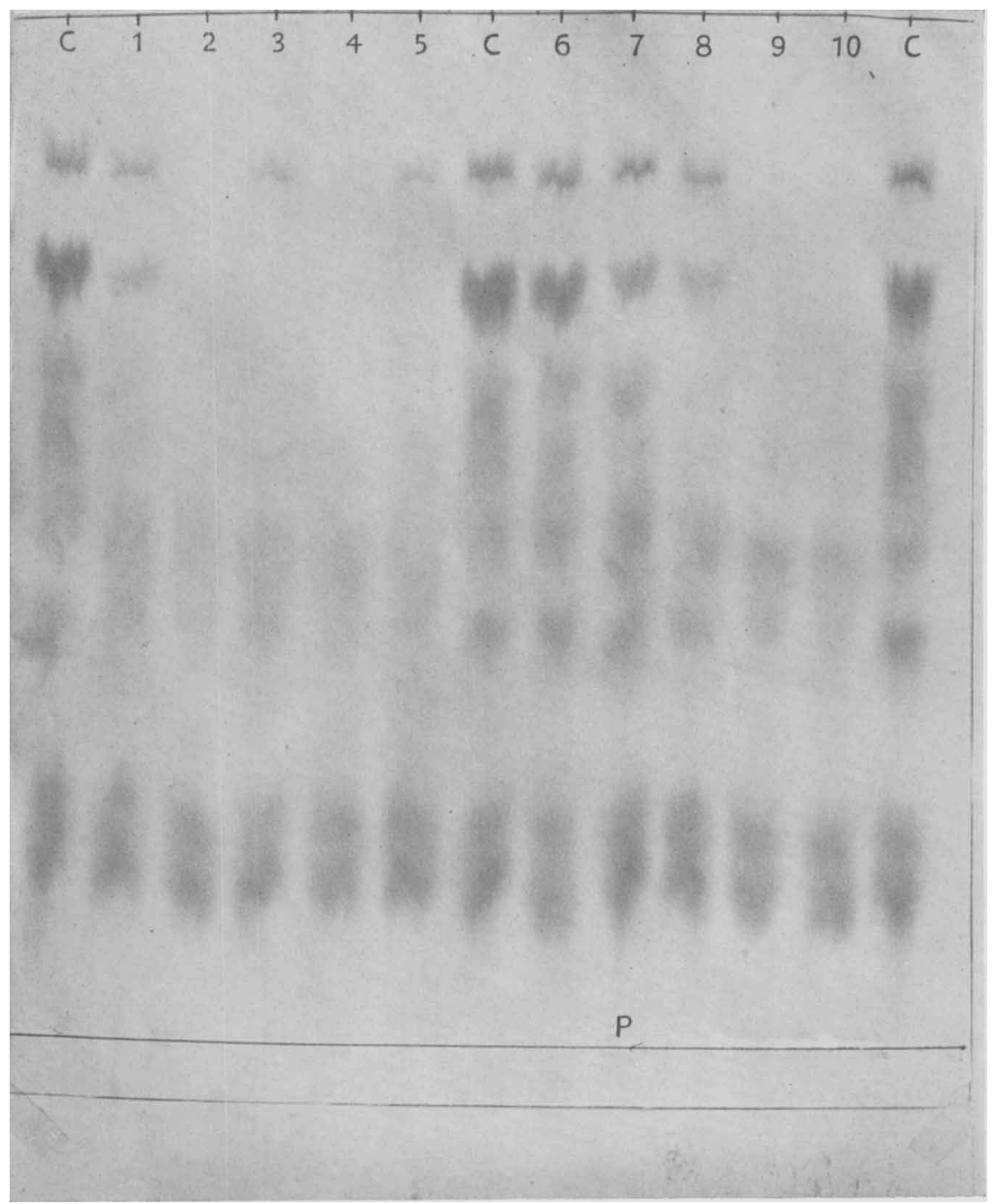

J. Ungar, A. M. James, P. W. Muggleton, H. F. Pegler \& E. G. Tomich-The cultivation of $\boldsymbol{H}$. pertussis in partially defined liquid media. Plate 1 
Consden, R., Gordon, A. H. \& Martin, A. J. P. (1944). Partition chromatography with paper. Biochem. J. 38, 224.

Dent, G. E. (1948). Partition chromatography with paper. Biochem. J. 43, 169.

Diemain, W. \& Fresenius, W. (1947). Chemical composition of yeasts- Dtsch. Lebensm. Rundsch. 43, 117 .

Farrell, L. \& TAYLOR, E. M. (1945). Notes on the production of Phase I pertussis vaccine in fluid medium. Canad. J. publ. Hlth, 36, 326.

Fisher, S. (1948). The behaviour of $\boldsymbol{H}$. pertussis in casein hydrolysate broth. Aust. J. exp. Biol. med. Sci. 24, 299.

Haworth, W. N., Peat, S. \& Sagroth, P. E. (1946). Amylose and amylopectin preparation. Nature, Lond., 157, 19.

Hehre, E. J., Carlson, A. S. \& Neill, J. M. (1947). Production of starch-like material from glucose-1-phosphate by diphtheria bacilli. Science, 106, 523.

HornirrooK, J. W. (1939). Cultivation of Phase I $\boldsymbol{H}$. pertussis in a semi-synthetic liquid medium. Publ. Hlth Rep., Wash., 54, (2), 847.

McLeOD, N. (1944). A simple and rapid method for the preservation of cultures by drying under vacuum. Inst. Med. Lab. Techn. p. 92.

Pollock, M. R. (1947). Growth of H. pertussis on medium without blood. Brit. J. exp. Path. 28, 295.

PoLLOck, M. R. (1949). The effects of long-chain fatty acids on the growth of Haemophilus pertussis and other organisms. Symp. Soc. exp. Biol. 3, 193.

Pope, C. G. \& Stevens, M. F. (1937). The determination of amino-nitrogen using a copper method. Biochem. J. 33, 1070.

Schосн, T. J. \& Wirliams, C. B. (1944). Adsorption of fatty acid by the linear component of corn starch. J. Amer. chem. Soc. 66, 1232.

Sumner, J. B., Krishman, P. S. \& Sisher, Eleanor B. (1947). An improved method for the preparation of co-enzyme I. Arch. Biochem. 12, 19.

UngAR, J. \& MUGGLeTON, P. W. (1948). Aluminium phosphate as precipitant of agglutinable and non-agglutinable strains of $H$. pertussis. Nature, Lond., 162, 734.

UnGar, J. \& Muggieton, P. W. (1949). The relationship of the aluminium phosphate precipitation of organisms of Haemophilus pertussis strains to their other biological properties. J. gen. Microbiol. 3, 353.

\section{EXPLANATION OF PLATE}

Chromatogram showing the utilization of amino-acids during the growth of a virulent and an avirulent strain of $H$. pertussis. 1-5: culture fluids after $5,7,0,12$ and 15 days' growth of the virulent strain (83E); 6-7: culture fluids after $5,7,9,12$ and 15 days' growth of the avirulent strain (154E); $C$ : control, unseeded culture medium; $P$ : phenol-water front. 